\title{
Verification of Phase Diagrams by Three-Dimension Computer Models
}

\section{Lutsyk VI ${ }^{1,2^{*}}$ and Vorob'eva'}

${ }^{1}$ Institute of Physical Materials Science, Siberian Branch of Russian Academy of Sciences, Russia ${ }^{2}$ Buryat State University Ulan-Ude, Russia

\begin{abstract}
Present paper is the survey of the works, dedicated to the elimination of contradictions in the publications, which describe the calculated and/or experimental results of investigations of the three-component systems phase diagrams. Special approach to the construction of phase diagrams in the form of their assembling from the surfaces and the phase regions into the three-dimensional (3D) computer model as the effective tool of the detection of the incorrect interpretation of the obtained experiment or of errors in the thermodynamic calculations of the phase diagrams fragments, caused by a deficiency in the initial information, is proposed. 3D computer models of Au-Ge-Sn, Au-Ge-Sb, Ag-Au-Bi, Ag-Sb-Sn, Au-Bi-Sb T-x-y diagram are considered.
\end{abstract}

Keywords: Phasediagrams; Computer simulation; Threedimensional Visualization

\section{Introduction}

Such known programs as Lukas Program, ThermoCalc, ChemSage, FACTSage, MTDATA, PanEngine, PANDAT are created for the calculations of phase equilibria. Thanks to them it became possible the use of more realistic models of the thermodynamic properties of phases, the calculation of phase diagrams in the complex two-component systems and the systems with the large number of components. The CALPHAD-method, which makes possible to generalize and to refine within the framework information about the phase equilibria and the thermodynamics of phases for one model, is most claimed today. It is effective means for decreasing the volumes of the experiments, necessary for understanding of phase transformations in the alloys and the ceramics. The CALPHAD ideology became the powerful means of theoretical studies and obtaining of adequate information about the phase equilibria. Thermodynamic properties and phase diagrams for the technologically important multi-component materials can be predicted with its use. The reliable thermodynamic descriptions of two-component systems are the basis of the data bases with such characteristics. However, the CALPHAD application is limited by a deficiency in reliable thermodynamic data and the weak possibilities of the visualization of three-dimensional objects. In addition to this, using of thermodynamic methods of the states diagram calculating is hindered by the need of evaluating the thermodynamic properties of phases (in the absence of experimental data) and the agreement of experimental data of phase equilibria with the thermodynamic models. The innovation technology of assembling the space models of multidimensional phase diagrams from the entire totality of the geometric images corresponding to them is proposed: "To decode the diagrams topology the schemes of uni- and invariant states had been elaborated. This sort of schemes with phase's routes designations makes possible to calculate the number of phase regions, surfaces and to know a type of every surface (plane, ruled or unruled surface). Detailed analysis of T-x-y diagrams geometrical constructions had been carried out with their aid, and their computer models had been designed" [1].

\section{D models of T-x-y diagrams: Approaches, the principles of} the construction

Basic principle of the design of the three-dimensional (3D) computer model of the ternary system T- $x$-y diagram is the assembling of three-dimensional objects of its surfaces and phase regions [2]. The $3 \mathrm{D}$ model constructing is fulfilled in several stages: 1) the twodimensional (2D) table and then the 3D scheme of uni- and invariant states (planes of invariant reactions and ruled surfaces), 2) the prototype (unruled surfaces), 3) transformation of the prototype into the real system model. It should be noted that, as many geometrically simple diagrams are already described in the known monographs (for instance, $[3,4]$, therefore the Reference book of $3 \mathrm{D}$ and $4 \mathrm{D}$ models of virtual $\mathrm{T}-\mathrm{x}-\mathrm{y}$ and $\mathrm{T}-\mathrm{x}-\mathrm{y}-\mathrm{z}$ diagrams of basic topological types is created (look about it, for instance, in [5]. And to construct the real system T-x-y diagram of a simple topology it suffices to take from the Reference book the finished model (or the combination of two-three simple models). The 3D model is obtained after the input of the concrete coordinates of base points (corresponding to invariant transformations in the binary and ternary system) and correction of the curvature of $\mathrm{T}-\mathrm{x}-\mathrm{y}$ diagram lines and surfaces. For instance, the liquidus of the Au-Ge-Sn=A-B-C phase diagram with six binary compounds (incongruently melting R1, $\mathrm{R} 2$ of the variable and $\mathrm{R} 4=\mathrm{AuSn}, \mathrm{R} 5=\mathrm{AuSn}_{4}$ of the constant concentration ( $\mathrm{R} 5$ is decomposed below $49.8^{\circ} \mathrm{C}$ ), $\mathrm{R} 3=\mathrm{AuSn}$ is the stoicheometry congruently melting compound, $\mathrm{R} 6=\mathrm{Au}_{5} \mathrm{Sn}$ exists below $179.3^{\circ} \mathrm{C}$ ) is the result of triangulation by the quasi-binary Ge-AuSn section, and each subsystem (Au-Ge-AuSn and AuSn-Ge-Sn) is the double combination of the classical topological type of the T-x-y diagram with a incongruently melting binary compound. But both subsystems are formed by two incongruently compounds (Figure 1). And the sub-solidus is complicated by the allotropy of tin (transformation of 2 modifications at low, $\sim 13^{\circ} \mathrm{C}$, temperatures). First step of the 3D model design is the analysis of the T-x-y diagram geometric structure using the uni- and invariant states scheme. This is the usual Sheil' phase reactions scheme [6], the trajectories of a change in the concentrations of the interacting phases in which are written below each three-phase reaction [2] (Tables 1 and 2). The first (with highest temperature) and second (with lowest one) points are accepted as the base points for each trajectory. They obtain designations (for instance, Table 1 and Figure 1): binary eutectic "e" and peritectic "p" with the subscripts $e_{A B}, e_{B C}, p_{A R 1}$, etc; concentrations of appropriate solid phases " $A$ " and " $B$ " as participants of, for instance, the eutectic reaction $\mathrm{L} \rightarrow \mathrm{A}+\mathrm{B}$; liquid concentrations in ternary eutectic " $\mathrm{E}$ ", quasi-

*Corresponding author: Lutsyk VI, Institute of Physical Materials Science Siberian Branch of Russian Academy of Sciences, Russia, Tel: +79247514406 ; E-mail: vluts@ipms.bscnet.ru

Received February 28, 2017; Accepted March 10, 2017; Published March 15 2017

Citation: Lutsyk VI, Vorob'eva (2017) Verification of Phase Diagrams by ThreeDimension Computer Models. Mod Chem Appl 5: 215. doi: 10.4172/23296798.1000215

Copyright: ( 2017 Lutsyk VI, et al. This is an open-access article distributed under the terms of the Creative Commons Attribution License, which permits unrestricted use, distribution, and reproduction in any medium, provided the original author and source are credited. 


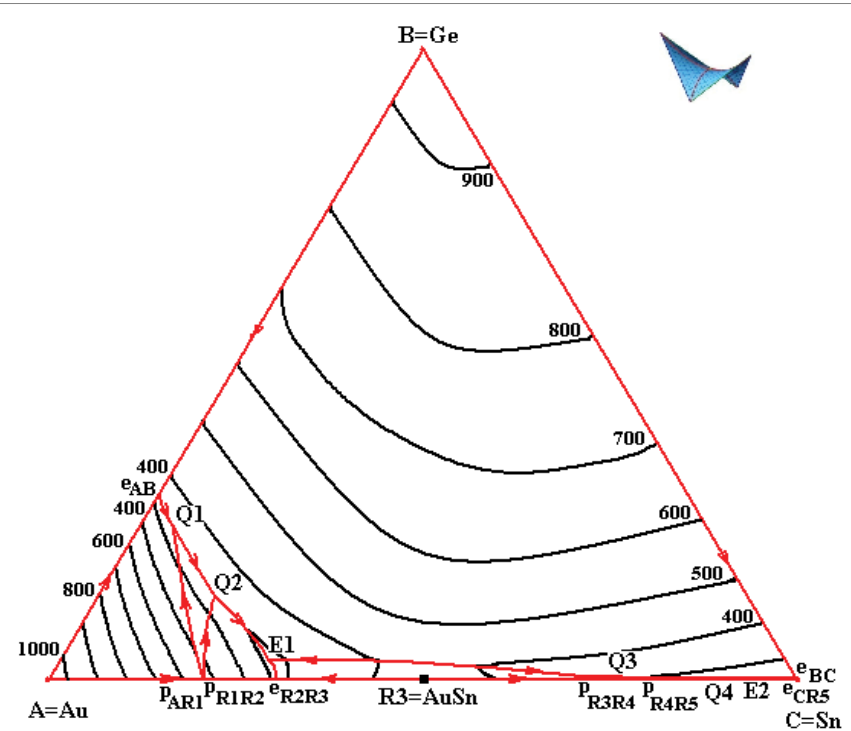

Figure 1: $\mathrm{X}-\mathrm{Y}$ projection of the Au-Ge-Sn=A-B-C T-x-y diagram 3D computer model.

peritectic "Q", peritectic "P", etc invariant reactions; concentrations of appropriate solid phases " $\mathrm{A}_{\mathrm{Q} 1}$ ", " $\mathrm{B}_{\mathrm{Q} 1}$ ", "R $1_{\mathrm{Q} 1}$ " (corresponding, for instance, to the reaction $Q 1: \mathrm{L}+\mathrm{A} \rightarrow \mathrm{B}+\mathrm{R} 1)$. Superscript " 0 " is assigned to based points of the temperature scale (on the lower face of the trigonal prism of the T-x-y diagram). These trajectories together with the appropriate lines of binary systems form the contours of the diagram surfaces [1]: curves $e_{A B} Q_{1}, p_{A R 1} Q_{1}$, corresponding to the liquid $L$, belong to inner contours of the liquidus surfaces (liquidus $-\mathrm{q}_{A}, \mathrm{q}_{B}, \mathrm{q}_{\mathrm{R} 1}$, etc), and appropriate them curves $\mathrm{A}_{\mathrm{B}} \mathrm{A}_{\mathrm{O} 1}$ and $\mathrm{A}_{\mathrm{R} 1} \mathrm{~A}_{\mathrm{O} 1}$ belong to the solidus surfaces (solidus - $s_{A}, s_{B}, s_{R 1}$, etc). The binary combinations of such lines are the directing curves for three ruled surfaces (ruled - superscript " $r$ ") on the boundaries of the three-phase region. Since these curves belong to the contours of liquidus (q) or solidus (s), than ruled surfaces on the boundaries of the region $\mathrm{L}+\mathrm{A}+\mathrm{B}$ are designated as $\mathrm{q}_{A B}^{\mathrm{r}}, \mathrm{q}_{B A}^{\mathrm{r}}, \mathrm{s}_{\mathrm{AB}}^{\mathrm{r}}$. If both the directing curves of a ruled surface are located on the contour of solidus surface, such ruled surface of "solidus type" is designated by the letter " $\mathrm{s}$ ". For instance, the solidus type ruled surface $\mathrm{s}_{\mathrm{AB}}^{\mathrm{r}}$ has directing curves $A_{B} A_{Q 1}$ and $A_{R 1} A_{Q 1}$, which belong to contours of solidus surfaces $\mathrm{s}_{\mathrm{A}}$ and $\mathrm{s}_{\mathrm{B}}$. But if one of the directing curve $\left(\mathrm{e}_{\mathrm{AB}} \mathrm{Q} 1\right)$ belongs to the liquidus surface $\left(q_{A}\right)$, then the ruled surface is named as "the liquidus type" $\left(\mathrm{q}_{\mathrm{AB}}^{\mathrm{r}}\right)$. As a result, according to the uni- and invariant states schema of the Au-Ge-Sn system (Table 1), one should expect besides six invariant four-phase transformations (two - eutectic E1, E2 and four quasi-peritectic $Q_{1}, Q_{2}, Q_{3}, Q_{4}$ ), indicated in the quasi-peritectictoid $Q_{5}$ : $\mathrm{R}_{2}+\mathrm{R}_{3} \rightarrow \mathrm{B}+\mathrm{R}_{6}$ and the eutectoid $\mathrm{E}_{3}: \mathrm{R}_{5} \rightarrow \mathrm{B}+\mathrm{C}+\mathrm{R}_{4}$ interactions, and also the polymorphous transformation $\mathrm{E}_{4}: \mathrm{C} \rightarrow \mathrm{C}_{1}+\mathrm{B}+\mathrm{R}_{4}$ in the sub-solidus. These "derived" from the uni- and invariant states scheme solid-phase invariant transformations $\mathrm{Q}_{5}, \mathrm{E}_{3}, \mathrm{E}_{4}$ are confirmed by the isopleths [7]. Thus, according to the uni- and invariant states scheme, the $\mathrm{Au}-\mathrm{Ge}-$ $\mathrm{Sn}=\mathrm{A}-\mathrm{B}-\mathrm{C}$ T- $\mathrm{x}-\mathrm{y}$ diagram consists of 173 surfaces $(8$ - liquidus and 8 solidus, 38 - solvus, 2 - transus, 81 ruled surfaces and 9 horizontal (isothermal) planes-complexes, corresponding to invariant reactions in the ternary system, and each of them is divided into 4 simplexes. Surfaces are borders of 65 phase regions ( 8 two-phase $\mathrm{L}+\mathrm{I}$ with liquid (I=A, B, C, R1-R5), 10 one-phase (I=A, B, C, C1, R1-R6), 20 two-phase $\mathrm{I}+\mathrm{J}$ without liquid, 13 three-phase $\mathrm{L}+\mathrm{I}+\mathrm{J}$ with liquid, 14 three-phase $\mathrm{I}+\mathrm{J}+\mathrm{K}$ without liquid). Further the tabular (2D) scheme is transferred into the graphic $3 \mathrm{D}$ form. Since the horizontal (isothermal) plane or the complex, which consists of four simplexes, corresponds to each four- phase transformation, then, it is possible to construct, for instance, for the Au-Ge-Sn system the quadrangle $\mathrm{A}_{\mathrm{O} 1} \mathrm{~B}_{\mathrm{O} 1} \mathrm{Q}_{1} \mathrm{R}_{1} \mathrm{Q}_{1}$ and other 8 complexes of different types for reactions $Q_{2}-Q_{5}, E_{1}-E_{4}$ (Table 1). Then it makes possible to draw three lines $\mathrm{e}_{\mathrm{AB}} \mathrm{Q}_{1}, \mathrm{~A}_{\mathrm{B}} \mathrm{A}_{\mathrm{Q1}}, \mathrm{B}_{\mathrm{A}} \mathrm{B}_{\mathrm{Q} 1}$ as the directing ones and to obtain the prototype of the three-phase region $\mathrm{L}+\mathrm{A}+\mathrm{B}$. The preliminary contours of other three-phase regions are depicted analogously. The $3 \mathrm{D}$ uni- and invariant states scheme is so constructed. Next step is to obtain the prototype of the T-x-y diagram by designing of the liquidus, solidus, solvus, transus surfaces. And last step includes the refinement of the curvature of the directing curves of ruled surfaces, closing the contours of unruled surfaces by curves of binary systems and correcting their isothermal lines. In this stage the $3 \mathrm{D}$ model of the real system T- $x-y$ diagram is formed. Finished T-x-y diagram 3D model allows to construct any arbitrarily assigned sections and to calculate mass balances of the coexisting phases in all stages of the crystallization for any arbitrarily assigned concentration [8]. Furthermore, the option of the determination of conditions for changing the type of three-phase reaction in any three-phase region is provided in 3D models [9]. Moreover 3D computer models of phase diagrams are an effective tool for the verification of those experimentally constructed isothermal sections and isopleths for checking the correctness of the interpretation of data, obtained from the experiment and the thermodynamic calculation $[10,11]$. The quality of each model depends on completeness and authenticity of initial data. But, independent of the initial information, even primitive initial model is capable to carry out such very important function as searching of contradictions in the description of phase diagrams geometric structures or data, obtained from the different publications. Such possibilities of 3D models can be seen on the examples of the using of the metal systems T-x-y diagrams - the bases of the creation of the materials, promising as the lead-free solders. Initial data for these 3D models are taken from the special atlases of phase diagrams for $\mathrm{Pb}$-free solders [7,12]. Their authors carried out for each system thorough selection and agreement of experimental data, which was being accompanied by the necessary thermodynamic calculations in the CALPHAD-technology. The additional experiment was fulfilled in the absence or the doubtfulness of data. Final result for each phase diagram of ternary system was represented in the form of the table of invariant reactions, $\mathrm{x}$ - $\mathrm{y}$ projection of liquidus and two-three isothermal sections and isopleths. Nevertheless, in spite of so scrupulous selection of represented data, they are not always deprived of contradictions. It should be noted that the $3 \mathrm{D}$ computer models construction is accompanied by the redesignation of components and compounds. For instance, $\mathrm{Au}, \mathrm{Ge}, \mathrm{Sn}$, low-temperature modification of tin, six binary compounds are denoted in the Au-Ge-Sn T-x-y diagram 3D model, correspondingly, as A, B, C, $\mathrm{C}_{1}, \mathrm{R}_{1}, \mathrm{R}_{2}$, etc. This makes it possible to avoid confusion in the designations, accepted in the CALPHAD, where it is taken into consideration for the designation of phases their crystal structure. For instance, compounds $\mathrm{AuSn}_{4}$ and AuSn are denoted in atlases of phase diagrams for lead-free solders in the volume, devoted to binary systems as AUSN4 и AU1SN, correspondingly, but in other volume of the same series as PTSN4_TYPE and NIAS_TYPE. Both germanium and lowtemperature modification of tin are designated by the same symbol DIAMOND_A4 (of their structure prototype).

Au-Ge-Sb: "Template" for the Au-Ge-Sb T-x-y diagram can be taken from the Reference book and, after input the coordinates (concentration-temperature) of base points, after the correction of the curvature of lines and surfaces, to obtain the 3D model of the real Au$\mathrm{Ge}-\mathrm{Sb} \mathrm{T}-\mathrm{x}-\mathrm{y}$ diagram with the compound $\mathrm{AuSb}_{2}$ (Figure 2). In this case the comparison of the 3D model isopleths 17 at \% Ge (Figure 3b) with that published (Figure 3a) makes it possible to reveal immediately the 
Citation: Lutsyk VI, Vorobeva VP (2017) Verification of Phase Diagrams by Three-Dimension Computer Models. Mod Chem Appl 5: 215. doi: 10.4172/2329-6798.1000215

Table 1: Uni- and invariant states scheme of the Au-Ge-Sn=A-B-C system. $A>B>p_{A R 1}>p_{R 1 R 2}>e_{B R 3}>R 3>e_{A B}>Q 1>Q 2>p_{R 3 R 4}>Q 3>e_{R 2 R 3}>E 1>p_{R 4 R 5}>>Q 4>C>e_{B C}>e_{C R 5}>>E 2>p_{R 2}^{R 2}>{ }_{R 2}>e_{C R 4}^{R 5}>E_{C}>C 1>e_{C 1 R 4}^{C}>e^{C}{ }_{B C 1}>E 4$

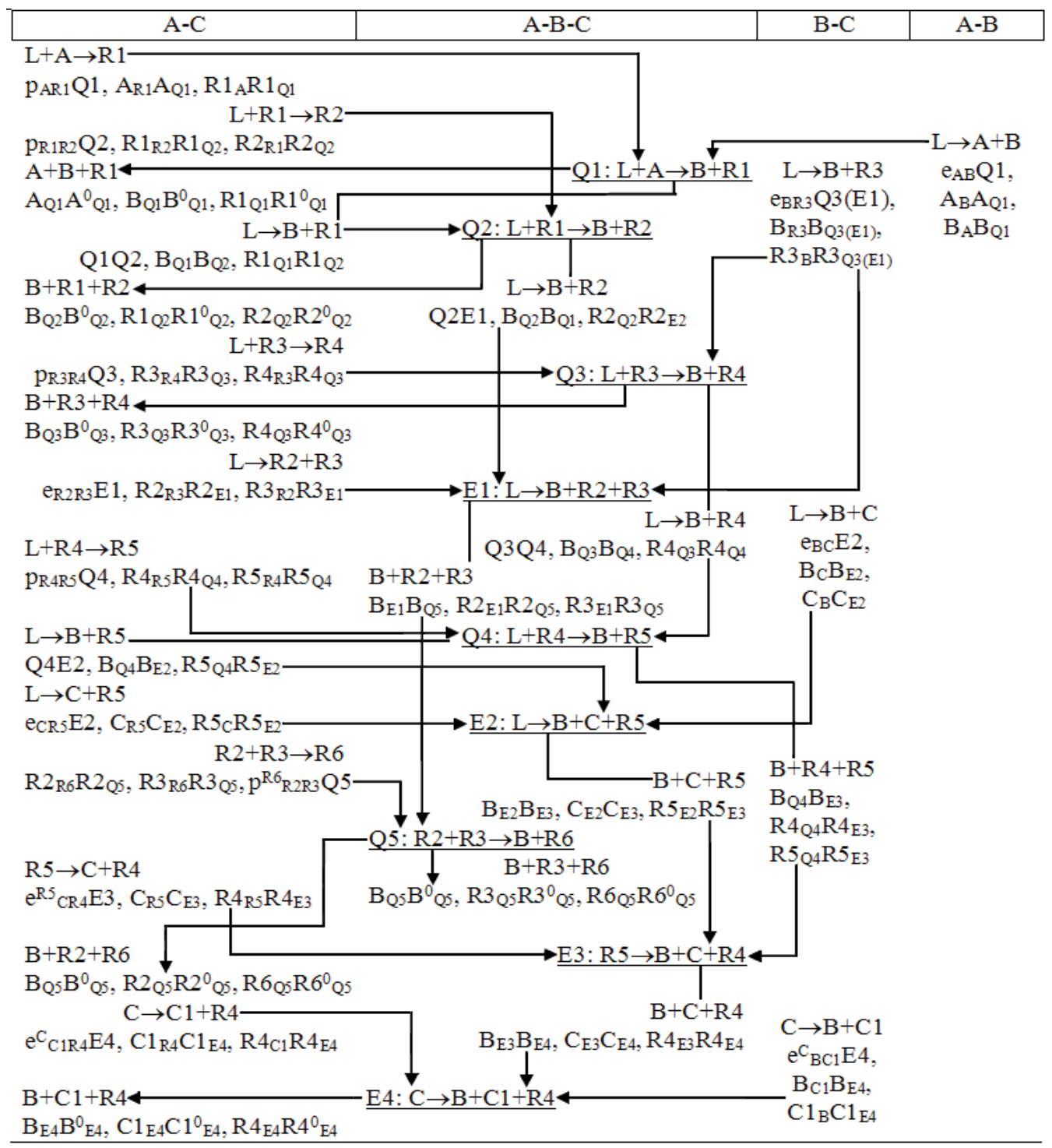

error of the latter: the intersection of the liquidus curve and the ruled surface section on the border of the regions $\mathrm{L}+\mathrm{Ge}$ and $\mathrm{L}+\mathrm{Ge}+\mathrm{Sb}$. It is worthwhile to note that the analogous section, parallel to side $\mathrm{Au}-\mathrm{Sb}$, but at other distance from Ge (not 17 at \%, but 15 at \%), in other paper, devoted to this system [13], is also constructed. The sections of liquidus and ruled surface are passed closely, but they do not intersect each other in this section.

Ag-Au-Bi: Despite the fact that the information, placed into the atlas, was thoroughly checked (according to its authors), the description of the Ag-Au-Bi system is contradictory: in the binary system $\mathrm{Au}-\mathrm{Bi}$, cited according to the data [14-19], the compound $\mathrm{Au}_{2} \mathrm{Bi}$ decomposes at the temperature $110^{\circ} \mathrm{C}$, whereas the solid solution on its basis in the ternary system isopleths exists also at $0^{\circ} \mathrm{C}$ (Figures $4 \mathrm{c}$ and $4 \mathrm{~d}$ ). To understand these contradictions, it is necessary to discuss the papers [14-18], the information from which in the form of an isothermal section and four isopleths were included into the atlas. The Ag-Au$\mathrm{Bi}=\mathrm{A}-\mathrm{B}-\mathrm{C} \mathrm{T}-\mathrm{x}-\mathrm{y}$ diagram has a simple geometric construction. It is formed by binary systems: with continuous series of solid solutions $(\mathrm{Ag}-\mathrm{Au}=\mathrm{A}-\mathrm{B})$, an eutectic $(\mathrm{Ag}-\mathrm{Bi}=\mathrm{A}-\mathrm{C})$, and an eutectic-peritectic (Au-
$\mathrm{Bi}=\mathrm{B}-\mathrm{C})$ with the binary incongruently melting compound $\mathrm{Au}_{2} \mathrm{Bi}=\mathrm{R}$. Liquidus consists of three fields of primary crystallization of: bismuth, solid solution based on the binary compound $\mathrm{Au}_{2} \mathrm{Bi}=\mathrm{R}$ and the solid solution $\operatorname{Ag}(\mathrm{Au})=\mathrm{A}(\mathrm{B})$. Liquidus surfaces intersect in the curves, connecting the binary eutectics $\mathrm{e}_{\mathrm{AC}}$ and $\mathrm{e}_{\mathrm{CR}}$ and the peritectic $\mathrm{p}_{\mathrm{BR}}$ (Figure 4) with the point $\mathrm{Q}$, corresponding to the invariant quasi-peritectic reaction $\mathrm{L}+\mathrm{Ag}(\mathrm{Au}) \rightarrow \mathrm{Bi}+\mathrm{Au}_{2} \mathrm{Bi}$ or $\mathrm{L}+\mathrm{A}(\mathrm{B}) \rightarrow \mathrm{C}+\mathrm{R}$. The compound $\mathrm{Au}_{2} \mathrm{Bi}$ exists up to $50^{\circ} \mathrm{C}$ according to the 2005 year paper [14] (Figure $5 \mathrm{a}$ ). This compound decomposes at $110^{\circ} \mathrm{C}$ (Figure $5 \mathrm{~b}$ ) according to the 2006 year work [16], and these data, as the most reliable, were chosen for the atlas [12]. However, the solid solution based on $\mathrm{Au}_{2} \mathrm{Bi}$ occurs in isopleths of below by temperatures from $450 \mathrm{~K}$ [17] and to $0^{\circ} \mathrm{C}[12]$, in the phase regions with the lowest temperatures. But if this compound decomposes in the binary system $\mathrm{Au}-\mathrm{Bi}$ at $110^{\circ} \mathrm{C}$, then the solid solution on its basis must indeed decompose, also, in the AgAu-Bi ternary system. This problem may be resolved by means of the 3D model too. In order to demonstrate this contradiction graphically, two versions of the $3 \mathrm{D}$ computer model of the T-x-y diagram were constructed: in one version the compound $\mathrm{Au}_{2} \mathrm{Bi}$ decomposes in the 
Table 2: Uni- and invariant states scheme of the Au-Bi-Sb=A-B-C system. $\quad A>C>p_{C R 2}>p_{A R 1}>e_{A R 2}>Q>B>e_{B R 1}>E>Y$

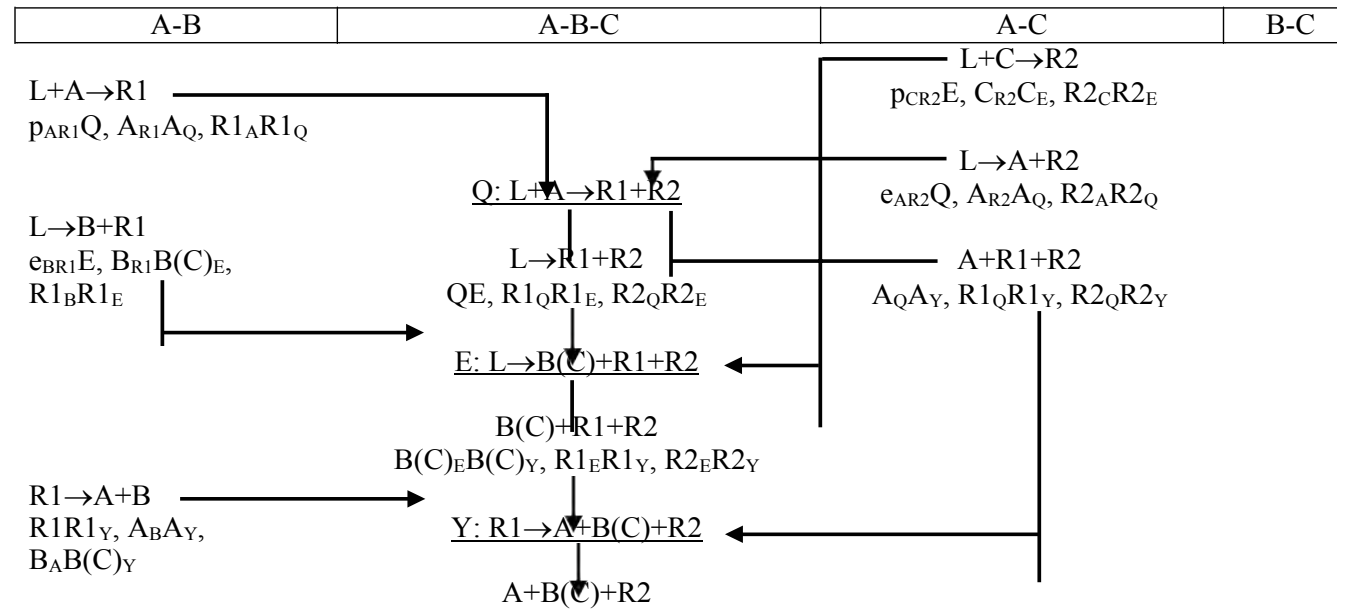

$\mathrm{A}_{Y} \mathrm{~A}_{\mathrm{Y}}^{0}, \mathrm{~B}(\mathrm{C})_{\mathrm{Y}} \mathrm{B}(\mathrm{C})_{\mathrm{Y}}^{0}, \mathrm{R} 2_{\mathrm{Y}} \mathrm{R} 2^{0}{ }_{\mathrm{Y}}$

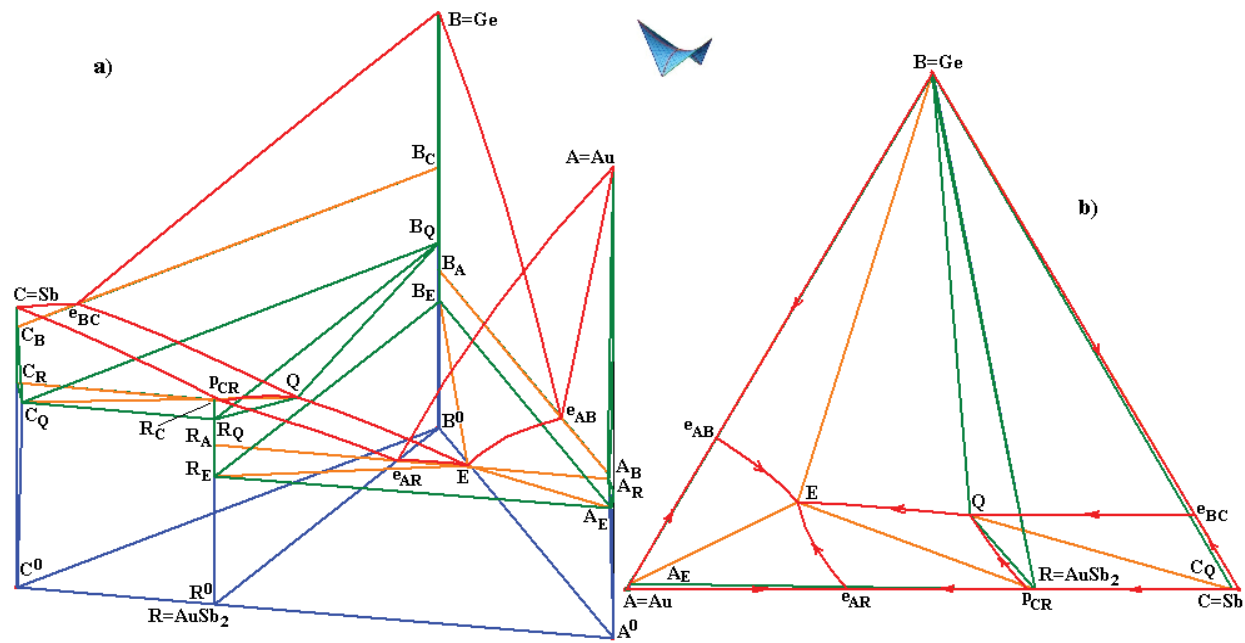

Figure 2: The Au-Ge-Sb=A-B-C T-x-y diagram 3D computer model (a), its $x-y$ projection (b)

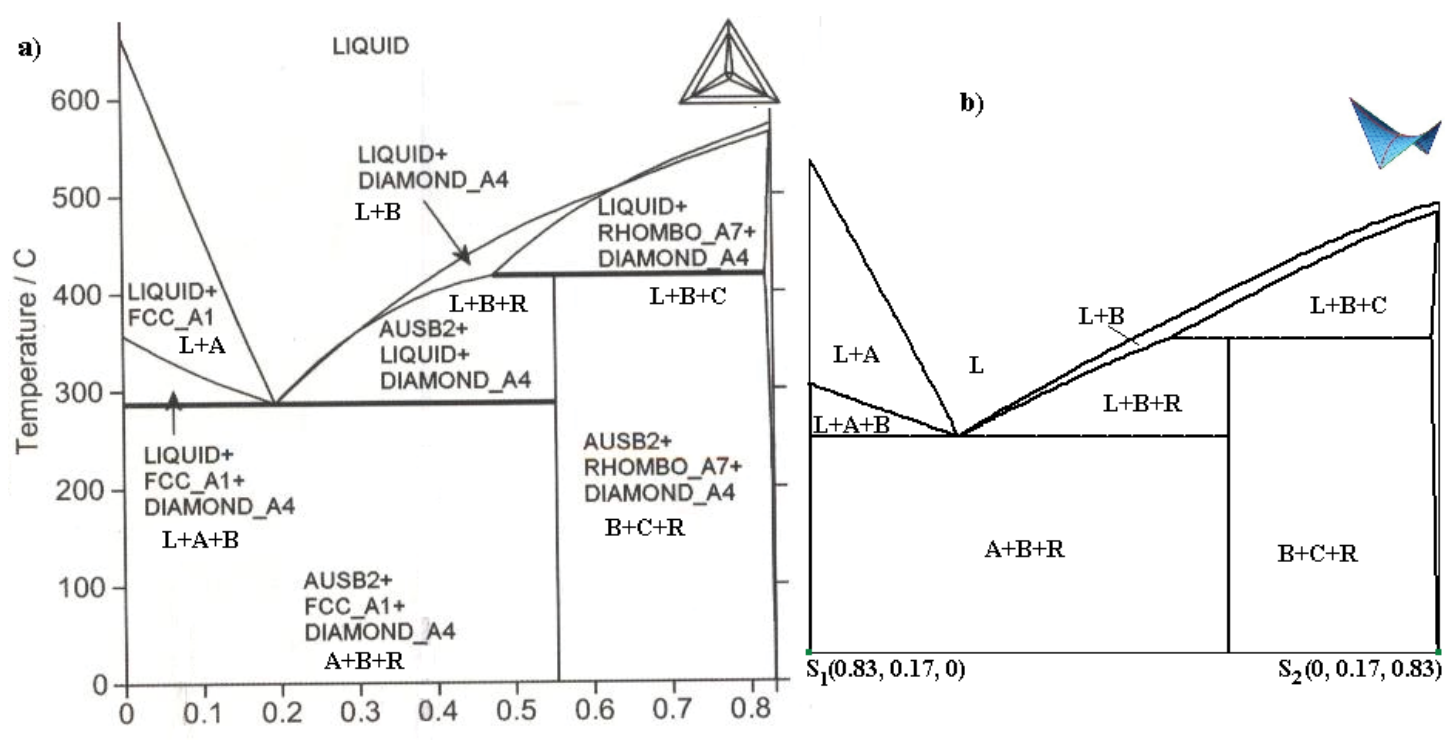

Figure 3: Isopleth 17 at\% Ge of the Au-Ge-Sb system 


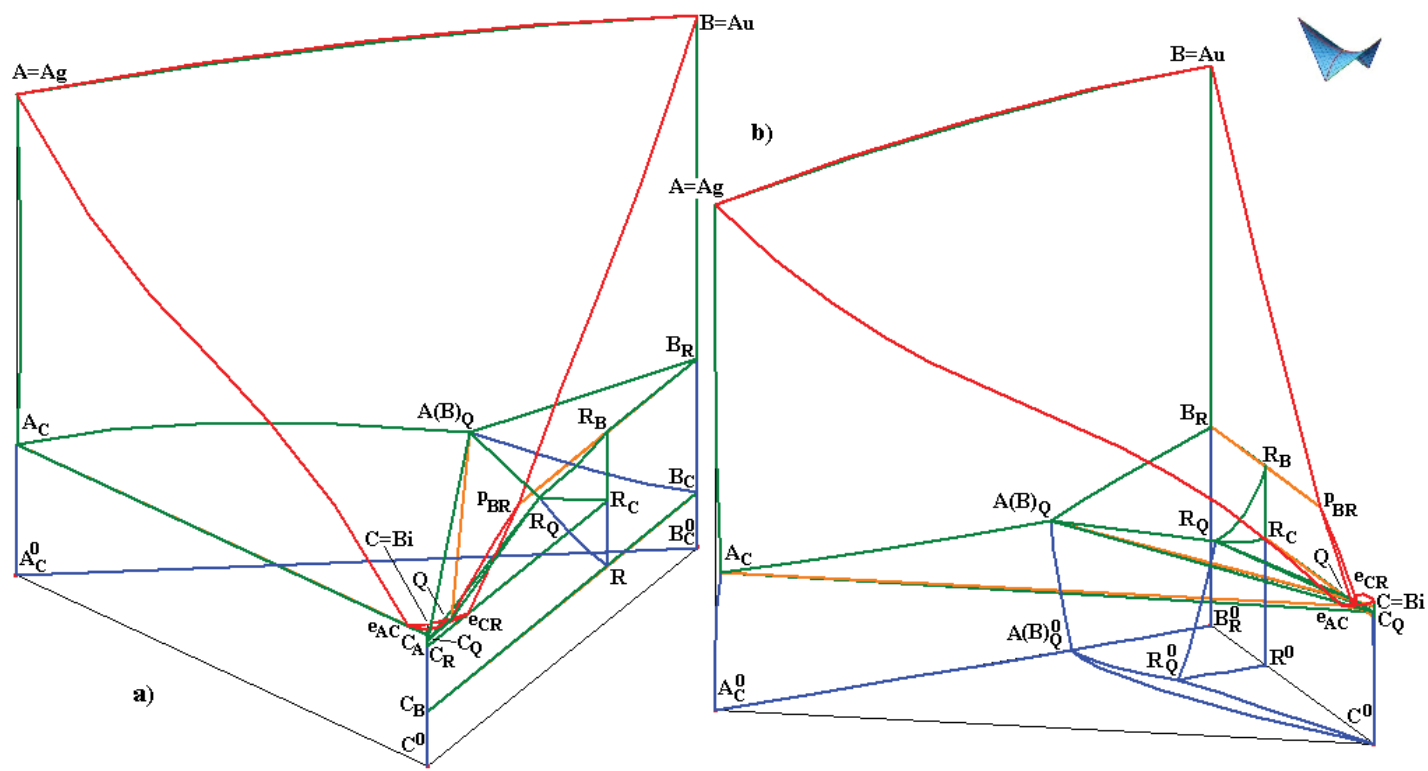

Figure 4: Designed by the data of [12] 3D computer model of the Ag-Au-Bi=A-B-C T-x-y diagram: with (a) and without (b) decomposition of the solid solution based on the compound $\mathrm{R}=\mathrm{Au}_{2} \mathrm{Bi}$.

binary system at $110^{\circ} \mathrm{C}$ and, correspondingly, the solid solution on its basis in the ternary system does not exist below by this temperature too (Figure 4a), in other version a decomposition is absent (Figure $4 \mathrm{~b})$. Both versions of the T-x-y diagram differ in the solvus surfaces and the boundaries of the three-phase region $\mathrm{A}(\mathrm{B})+\mathrm{C}+\mathrm{R}$. If the solid solution on the basis of the compound $\mathrm{R}$ decomposes, then the process $\mathrm{R} \rightarrow \mathrm{A}(\mathrm{B})+\mathrm{C}$ is closed within the three-phase region with boundaries given by the directing curves $R_{Q} R, A(B){ }_{Q} B_{R}, C_{Q} C_{R}$ (Figure $4 a$ ). If the solid solution based on the compound $\mathrm{R}$ in the ternary system does not decompose, then the region $\mathrm{A}(\mathrm{B})+\mathrm{C}+\mathrm{R}$ below the horizontal plane $\mathrm{Q}$ is bounded by three ruled surfaces with the directing curves $R_{Q} R^{0}{ }_{Q}, A(B)$ ${ }_{\mathrm{Q}} \mathrm{A}(\mathrm{B})^{0}{ }_{\mathrm{Q}}, \mathrm{C}_{\mathrm{Q}} \mathrm{C}^{0}$ (Figure $4 \mathrm{~b}$ ). Both versions of the $\mathrm{T}-\mathrm{x}-\mathrm{y}$ diagram consists of 28 surfaces ( 3 liquidus and 3 solidus, 6 solvus, 12 ruled surfaces and 4 horizontal planes, corresponding to simplexes of the complex of the invariant transformation $\mathrm{Q}: \mathrm{L}+\mathrm{A}(\mathrm{B}) \rightarrow \mathrm{C}+\mathrm{R})$ and 14 phase regions. Border solution on the compound $\mathrm{R}$ base has the linear region of the homogeneity. Bordering it surfaces of two solvus $v_{R_{A}(B)}\left(R_{B} R R_{Q}\right.$ or $\left.\mathrm{R}_{\mathrm{B}} \mathrm{R}_{\mathrm{Q}} \mathrm{R}_{\mathrm{Q}}^{0} \mathrm{R}_{\mathrm{B}}^{0}\right), \mathrm{v}_{\mathrm{RC}}\left(\mathrm{R}_{\mathrm{C}} \mathrm{RR}_{\mathrm{Q}}\right.$ or $\left.\mathrm{R}_{C} \mathrm{R}_{\mathrm{Q}} \mathrm{R}_{\mathrm{Q}}^{0} \mathrm{R}^{0}{ }_{\mathrm{C}}\right)$ and solidus $\mathrm{s}_{\mathrm{R}}\left(\mathrm{R}_{\mathrm{B}} \mathrm{R}_{\mathrm{Q}} \mathrm{R}_{\mathrm{C}}\right)$ have a triangular shape (Figure $4 \mathrm{~b}$ ). A conclusion about the temperature boundaries of the compound $\mathrm{Au}_{2} \mathrm{Bi}$ existence cannot be made from the phase reactions scheme of [14]. It corresponds to the uni- and invariant states scheme, which does not consider its decomposition. Note also that phase reactions are written in the scheme of [14] incorrectly: the peritectic reaction $\mathrm{L}+\mathrm{Au} \rightarrow \mathrm{Au}_{2} \mathrm{Bi}$ and the eutectic one $\mathrm{L} \rightarrow \mathrm{Au}_{2} \mathrm{Bi}+\mathrm{Bi}$ are changed by the places. Moreover the eutectic reaction is written as $\mathrm{L} \rightarrow(\mathrm{Ag})+(\mathrm{Bi})$. Isopleths 20 at $\% \mathrm{Ag}$ (Figure $5 \mathrm{a}-\mathrm{c}), 50$ at $\% \mathrm{Bi}, 85 \mathrm{at} \% \mathrm{Bi}$, $\mathrm{Ag}: \mathrm{Au}=1: 4$ and the isothermal section $\mathrm{T}=230^{\circ} \mathrm{C}$ are shown in papers $[12,17]$. There is no contradictions of the $3 \mathrm{D}$ model and the published sections, including the isothermal section at $\mathrm{T}<\mathrm{T}_{\mathrm{O}}$ in both versions and the high-temperature part of the $\mathrm{T}-\mathrm{x}$-y diagram (higher than reaction $\mathrm{Q}$ at $\mathrm{T}_{\mathrm{O}}=251.9^{\circ} \mathrm{C}$ ). If the compound $\mathrm{Au}_{2} \mathrm{Bi}$ decomposes, the versions of the 20 at \% Ag isopleth, published in [12] (Figure 4c) and [17,18] (Figure $5 \mathrm{~d}-\mathrm{f}$ ), are reproduced by the $3 \mathrm{D}$ model, where the section $\mathrm{S}_{1} \mathrm{~S}_{2}$ of the three-phase region, designated in [12] as FCC1_A1+RHOMBO_A7+AU2BI_ $C 15$, is bounded by curves 6-8 and 7-9 (Figure 5e). However, in the case of the based on R solid solution decomposition the vertical plane $\mathrm{S}_{1} \mathrm{~S}_{2}$ intersects the ruled surfaces $\mathrm{q}^{\mathrm{rR}}$ and $\mathrm{s}^{\mathrm{rR}}{ }_{\mathrm{BC}}$ (to notate the boundaries of the three-phase region with a phase reaction $\mathrm{R} \rightarrow \mathrm{A}(\mathrm{B})+\mathrm{C}$ without liquid, the superscript " $R$ " is added) through curves 7-8 and 6-8. The last are the boundaries of the three-phase region $\mathrm{Ag}(\mathrm{Au})+\mathrm{Bi}+\mathrm{Au}_{2} \mathrm{Bi}=\mathrm{A}(\mathrm{B})+\mathrm{C}+\mathrm{R}$ (Figure 5f). Since the three-phase region $\mathrm{Ag}(\mathrm{Au})+\mathrm{Bi}+\mathrm{Au}_{2} \mathrm{Bi}$ in the published in $[11,17]$ isopleths exists up to $0^{\circ} \mathrm{C}$, then it is assumed that the temperature of the $\mathrm{Au}_{2} \mathrm{Bi}$ compound decomposition after addition of the third component $(\mathrm{Ag})$ reduces due to the formation of the solid solution $\operatorname{Ag}(\mathrm{Au})$. However, the participation of the compound in the invariant reaction $\mathrm{L}+\mathrm{Ag}(\mathrm{Au}) \rightarrow \mathrm{Bi}+\mathrm{Au}_{2} \mathrm{Bi}$ at $251.9^{\circ} \mathrm{C}$ and without the decomposition of the compound $\mathrm{Au}{ }_{2} \mathrm{Bi} \rightarrow \mathrm{Ag}(\mathrm{Au})+\mathrm{Bi}$ at $110^{\circ} \mathrm{C}$ suggests that the three-phase region $\mathrm{Ag}(\mathrm{Au})+\mathrm{Bi}+\mathrm{Au}_{2} \mathrm{Bi}$ exists only within the temperature interval $251.9-110^{\circ} \mathrm{C}$. The two-phase region $\mathrm{Ag}(\mathrm{Au})+\mathrm{Bi}$ is lower than this region under the ruled surface $A(B){ }_{Q} C_{Q} C_{B} B_{C}$ in all concentration diapason. Because at ultralow temperatures, according to the third law of thermodynamics, the continuous solid solution $\mathrm{Ag}(\mathrm{Au})$ should undergo decomposition into components [20,21] this twophase region should be replaced by the three-phase region $\mathrm{Ag}+\mathrm{Au}+\mathrm{Bi}$.

Ag-Sb-Sn: Analogous contradictions are in the description of the Ag-Sb-Sn T-x-y diagram. From one side, the binary compound $\mathrm{Sb}_{2} \mathrm{Sn}_{3}$ in the Ag-Sb-Sn T-x-y diagram, represented in [22-24], exists at temperatures up to $0^{\circ} \mathrm{C}$. With another side, this compound decomposes at $242.4^{\circ} \mathrm{C}$ in [12]. Its existence is limited by the same temperature in the analogous system Ni-Sb-Sn too. Consequently, the conditions for the compound $\mathrm{Sb}_{2} \mathrm{Sn}_{3}$ existence require additional experimental study. But now the 3D model is designed in two versions. The first one corresponds to [22-24] with the polymorphous transformations in the eutectoid reaction, and the 3D model consists of 99 surfaces and 62 phase regions. In the different version, constructed according to the data of [12], one additional eutectoid reaction precedes the polymorphous transformation, and the 3D model consists of 109 surfaces and 66 phase regions.

Au-Bi-Sb: The results of experimental study and thermodynamic correlation using the CALPHAD-technology of the $\mathrm{Au}-\mathrm{Bi}-\mathrm{Sb}=\mathrm{A}-\mathrm{B}-\mathrm{C}$ system with the compounds $\mathrm{Au}_{2} \mathrm{Bi}=\mathrm{R}_{1}$ and $\mathrm{AuSb}_{2}=\mathrm{R}_{2}$, are presented in $[25,26]$. Earlier six isopleths had been shown in [27], which then were also constructed in [26]. The authors of atlas [12] after the analysis of 

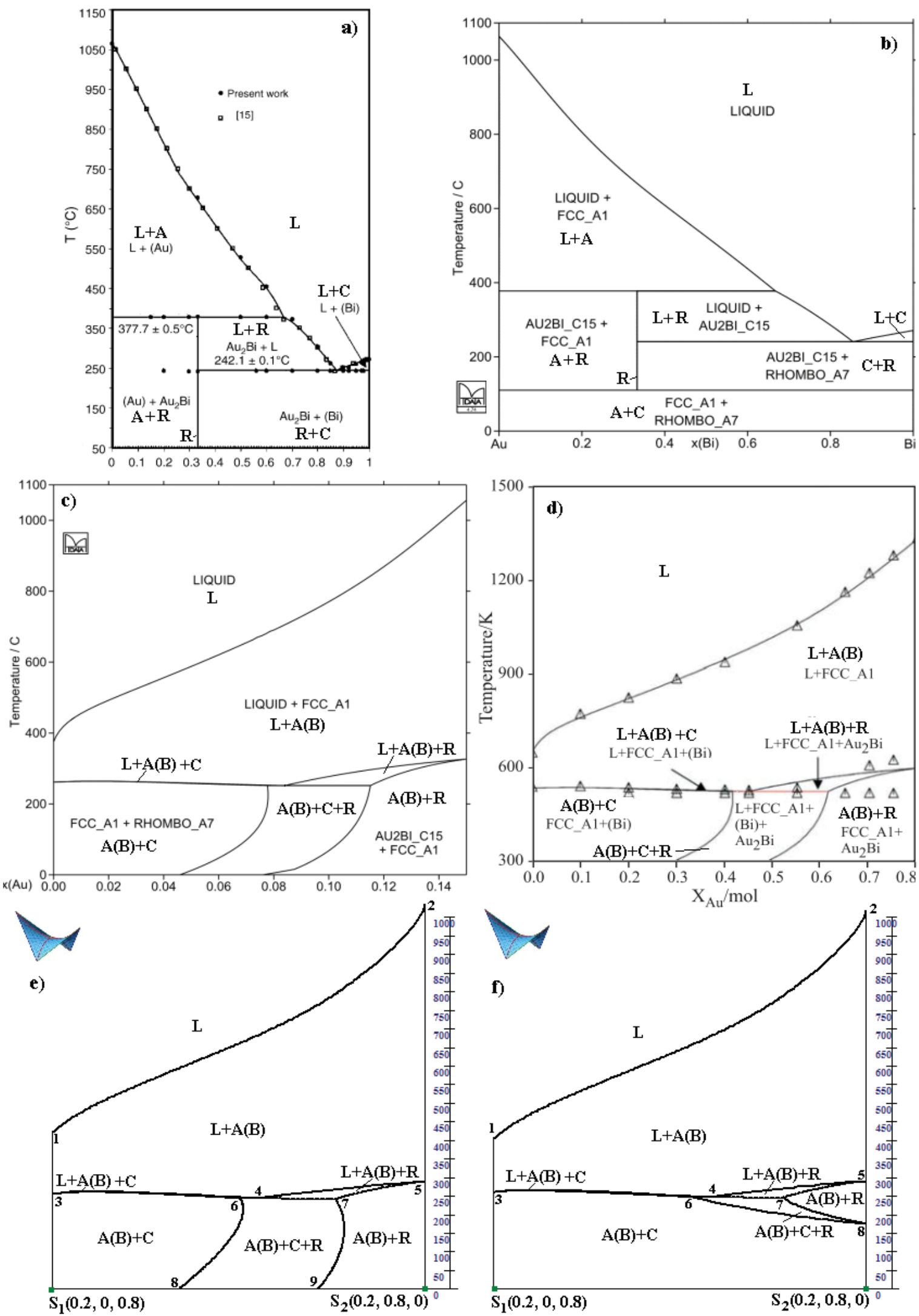

Figure 5: Binary system Au-Bi according to the data of [12] (a) and [17] (b): isopleth $\mathrm{S}_{1}(0.2,0.8,0)-\mathrm{S}_{2}(0.2,0,0.8)$ of the Ag-Au-Bi; [12] (c): [17] (d): 3D model, designed according to the data of [12] with (e) and without (f) decomposition of the solid solution based on the compound $\mathrm{R}=\mathrm{Au}_{2} \mathrm{Bi}$. 
these publications preferred the results of the data of [26], but correcting and obtaining "the better agreement in comparison with the experimental results". The region of the homogeneity of the solid solution $\mathrm{Bi}(\mathrm{Sb})=\mathrm{B}(\mathrm{C})$ is shown in [26] in the isothermal section $300^{\circ} \mathrm{C}$. Analogous section is used for the illustration of the phase diagrams calculation results by the method of the convex hulls [28]. However, the binary system $\mathrm{Bi}-\mathrm{Sb}$ adjoins not with the solid solution $\mathrm{B}(\mathrm{C})$ region, but with the two-phase region $\mathrm{Bi}(\mathrm{Sb})+\mathrm{AuSb}_{2}=\mathrm{B}(\mathrm{C})+\mathrm{R}_{2}$, containing the compound with the third component (gold), in the same section, published in the atlas and in [25]. So, versions of the Au-Bi-Sb T-x-y diagram $3 \mathrm{D}$ computer model were also used for explaining this contradiction in iso- and the polythermal sections, constructed by the different authors. Each version is designed according to the data of concrete publication and reproduces all given there sections and projections. This makes it possible to compare the sections of diagrams, obtained from different works. According to the atlas data, two invariant reactions - quasi-peritectic Q: $\mathrm{L}+\mathrm{A} \rightarrow \mathrm{R}_{1}+\mathrm{R}_{2}$ at $296^{\circ} \mathrm{C}$ and eutectic $\mathrm{E}$ : $\mathrm{L} \rightarrow \mathrm{B}(\mathrm{C})+\mathrm{R}_{1}+\mathrm{R}_{2}$ at $239.2^{\circ} \mathrm{C}$ with participation of the solid solution of bismuth with antimony $\mathrm{B}(\mathrm{C})$ takes a place in the $\mathrm{Au}-\mathrm{Bi}$-Sb system. However, the $\mathrm{Au}_{2} \mathrm{Bi}=\mathrm{R}_{1}$ compound decomposes in the binary system at $110^{\circ} \mathrm{C}$ and it is absent in the atlas sections at temperatures lower than $110^{\circ} \mathrm{C}$. Consequently, it is necessary to add into the phase reactions scheme the invariant decomposition $\mathrm{Y}: \mathrm{R}_{1} \rightarrow \mathrm{A}+\mathrm{B}(\mathrm{C})+\mathrm{R}_{2}$ (Table 2). Formal enumeration of surfaces and phase regions gives according to the uni- and invariant states scheme (Table 2) 4 liquidus and 4 solidus surfaces, 12 surfaces of solvus, the cupola of the disintegration of the solid solution $\mathrm{B}(\mathrm{C}), 3$ complexes of the invariant reactions ( $Q$ at $296^{\circ} \mathrm{C}$, $\mathrm{E}$ at $239.2^{\circ} \mathrm{C}, \mathrm{Y}$ at $\sim 110^{\circ} \mathrm{C}$ ), divided each into 4 horizontal triangular simplexes, 15 ruled surfaces or borders of 5 three-phase regions with liquid and 12 ruled surfaces as borders of 4 three-phase regions without liquid. Concentration coordinates $(0,0.948,0.052)$ of the vertex $B(C)_{E}$ of the complex, which corresponds to the eutectic reaction in the ternary system, are indicated in the atlas [12], as if this point belongs to the $\mathrm{Bi}-\mathrm{Sb}=\mathrm{B}-\mathrm{C}$ binary system. Since this is impossible, the point $\mathrm{B}(\mathrm{C})_{\mathrm{E}}$ was displaced in the computer model inside the prism to position $(0.010,0.948,0.042)$. Because of this the solidus $\mathrm{s}_{\mathrm{B}(\mathrm{C})}$ surface ceased to belong to edge B-C. Surfaces of solidus $\left(\mathrm{s}_{\mathrm{R} 1}\right)$ and solvus $\left(\mathrm{v}_{\mathrm{R} 1 \mathrm{~A}}, \mathrm{~V}_{\mathrm{R} 1 \mathrm{~B}(\mathrm{C})}\right.$, $\mathrm{V}_{\mathrm{R} 1 \mathrm{R} 2}$ ), corresponding to the stoichiometric compound R1, which does not exist below $110^{\circ} \mathrm{C}$, practically coincide with the vertical line $\mathrm{R} 1$ within the temperature interval $377.5-110^{\circ} \mathrm{C}$, where $377.5^{\circ} \mathrm{C}$ is the temperature of the peritectic $\mathrm{p}_{\mathrm{AR} 1}$. Border solution based on the compound $\mathrm{R}_{2}$ has the linear homogeneity region. The part of the solidus $\mathrm{s}_{\mathrm{R} 2}\left(\mathrm{R}_{2 \mathrm{~A}} \mathrm{R}_{2 \mathrm{Q}} \mathrm{R}_{2 \mathrm{E}} \mathrm{R}_{2 \mathrm{C}}\right)$ corresponding to it takes the triangular shape $R_{2 C} R_{2 A} R_{2 Q}$, and the line $R_{2 Q} R_{2 E}$ coincides with the line $R_{2 C} R_{2 E}$ (Figure 6a). Analogously the surfaces of solvus $v_{R 2 A} \quad\left(R_{2 A} R_{2 Q} R_{2 Y} R_{2}^{0}\right), \quad v_{R 2 \_B(C)}$ $\left(R_{2 C} R_{2 E} R_{2 Y} R_{2}^{0}\right), \quad v_{R 2 R 1} \quad\left(R_{2 Q} R_{2 E} R_{2 Y}\right)$ have in the same plane the configurations with the triangular fragments $\mathrm{V}_{\mathrm{R} 2 \mathrm{~A}}\left(\mathrm{R}_{2 \mathrm{~A}} \mathrm{R}_{2 \mathrm{O}} \mathrm{R}_{2 \mathrm{Y}}\right), \mathrm{v}_{\mathrm{R} 2 \mathrm{~B}(\mathrm{C})}$ $\left(R_{2 C} R_{2 E} R_{2 Y}\right), v_{R 2 R 1}\left(R_{2 Q} R_{2 E} R_{2 Y}\right)$, corresponding to the solidus $s_{R 2}$. But since in the $\mathrm{Au}-\mathrm{Sb}=\mathrm{A}-\mathrm{C}$ system the compound $\mathrm{R}_{2}$ is stoichiometric, and points $\mathrm{R}_{2 \mathrm{~A}}^{\circ}$ and $\mathrm{R}_{2 \mathrm{C}}^{\circ}$, practically coincide with the vertical line in the point $R_{2}$, they are supplemented in the ternary system by the point, denoted in the uni- and invariant states scheme (Table 2) as $\mathrm{R}_{2}^{0}{ }_{\mathrm{Y}}$, they all obtains the same designation $\mathrm{R}_{2}^{\circ}$, corresponding to the prism base (Figure 6a). So, the Au-Bi-Sb T-x-y diagram consists of 60 surfaces and 24 phase regions, including six surfaces $\left(\mathrm{s}_{\mathrm{R1}}, \mathrm{v}_{\mathrm{AB}(\mathrm{C})}, \mathrm{v}_{\mathrm{AR1}}, \mathrm{V}_{\mathrm{R} 1 \mathrm{~A}}, \mathrm{~V}_{\mathrm{R} 1 \mathrm{~B}(\mathrm{C})}\right.$, $\mathrm{V}_{\mathrm{R} 1 \mathrm{R} 2}$ ), which practically degenerated in the vertical lines $A$ and $\mathrm{R}_{1}$ and

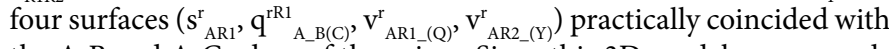
the A-B and A-C edges of the prism. Since this 3D model corresponds to the basic principles of geometric thermodynamics (the phase rule and the law of adjoining phase regions), then it makes it possible to explain the reasons for contradictions in the publications of different authors. The curve of the solid solution $\mathrm{Bi}(\mathrm{Sb})$ disintegration on $\mathrm{Bi}$ and
$\mathrm{Sb}$ is depicted at temperatures lower than $200^{\circ} \mathrm{C}$ in the published in [12] the Bi-Sb binary system phase diagram (Figure 7). This curve obviously assigns the solid solution disintegration cupola in the $\mathrm{Au}-\mathrm{Bi}-\mathrm{Sb}$ ternary system. Track of a section can be seen in the atlas [12] in the 20 at $\% \mathrm{Bi}$ isopleth (Figure 8a). However the two-phase region $\mathrm{Bi}+\mathrm{Sb}$ is denoted in this section as the three-phase : $\mathrm{Bi}+\mathrm{Sb}+\mathrm{AuSb}_{2}=\mathrm{B}+\mathrm{C}+\mathrm{R} 2$ (or $\mathrm{RHOMBO}_{-}$ A7+RHOMBO_A7+AUSB2 in the designations of [12]). The twophase region $\mathrm{Bi}(\mathrm{Sb})+\mathrm{AuSb}_{2}=\mathrm{B}(\mathrm{C})+\mathrm{R} 2$ (RHOMBO_A7+AUSB2) is denoted above it. Thus, the phase regions, which contain the compound with gold, adjoin with the binary system, formed by bismuth and antimony. Perhaps, the authors [12] were mistaken in the designations of these phase regions, and the compound $\mathrm{AuSb}_{2}=\mathrm{R}_{2}$ should be removed, after renaming the two-phase region to the single-phase (the solid solution of bismuth with antimony), and the three-phase to the two-phase (disintegration of this solid solution). But the single-phase region RHOMBO_A7 would then be adjacent to three-phase regions $\mathrm{Bi}$ $(\mathrm{Sb})+\mathrm{Au}_{2} \mathrm{Bi}+\mathrm{AuSb}_{2}=\mathrm{B}(\mathrm{C})+\mathrm{R} 1+\mathrm{R} 2\left(\mathrm{RHOMBO} \_\mathrm{A} 7+\mathrm{AU} 2 \mathrm{BI}\right.$ $\mathrm{C} 15+\mathrm{AUSB} 2)$ and $\mathrm{L}+\mathrm{Bi}(\mathrm{Sb})+\mathrm{AuSb}_{2}=\mathrm{L}+\mathrm{B}(\mathrm{C})+\mathrm{R} 2 \quad\left(\mathrm{~L}+\mathrm{RHOMBO}_{-}\right.$ $\mathrm{A} 7+\mathrm{AUSB} 2$ is not designed in [12], violating the law of adjoining phase regions. As was mentioned above, authors of [12] preferred the results of the work [26]. It is necessary to note that the binary system Bi-Sb is examined in [26] at temperatures above $500 \mathrm{~K}$ - above the binodal curve and the temperature $400 \mathrm{~K}$ is the minimum in all isopleths. The disintegration cupola of the solid solution $\mathrm{Bi}(\mathrm{Sb})$ is absent in the sections, published in [26], and it is possible only to assume that it would appear at temperatures below $400 \mathrm{~K}$. However, there is no contradiction in the designations of phase regions, because the singlephase region of the solid solution $\mathrm{Bi}(\mathrm{Sb})$ adjoins directly to the $\mathrm{Bi}-\mathrm{Sb}$ system as, for instance, in the 20 at \% Bi isopleth (Figure 8c). On the other hand, the binodal curve assigns the region of the disintegration of the solid solution in the Bi-Sb binary system, and it can be seen the track of its section not only in isopleths in the atlas [12] (Figure 8a), but also in the paper [25], moreover with the same contradictory designations of phase regions near the Bi-Sb system. To explain the reasons of the contradiction in determining phase regions and to understand, whether the authors considered the decomposition of the solid solution $\mathrm{Bi}(\mathrm{Sb})=\mathrm{B}(\mathrm{C})$ in the binary system $\mathrm{Bi}-\mathrm{Sb}$, on the one hand in the publications $[12,25]$, and in $[26,27]$ on the other hand, three versions of the Au-Bi-Sb T-x-y diagram 3D model were designed according to the data of [12] (Figure 6), [25] and [26]. In contrast to [12], the compounds $\mathrm{Au}_{2} \mathrm{Bi}=\mathrm{R} 1$ and $\mathrm{AuSb}_{2}=\mathrm{R}_{2}$ are treated as stoichiometric in [25], and there is no disintegration of the solid solution $\mathrm{Bi}(\mathrm{Sb})$ in [26]. If "no", then isopleths in [26] (Figure 8c) and [27] are accurate. And they, like the corresponding 3D model isopleth (Figure 8d), depicts the boundaries of the solid solution $\mathrm{Bi}(\mathrm{Sb})=\mathrm{B}(\mathrm{C})$ region as traces of sections of the surfaces of solidus and solvus (curves 5-6 and 6-18). They are very close to the temperature axis and are hard to see, but they are present in the sections. If "yes", and the solid solution decomposes in the system $\mathrm{Bi}-\mathrm{Sb}$, then a curve corresponds to it in the T-x diagram (Figure 7). It generates the disintegration cupola in the ternary system, which is present in the isopleths of [12] (Figure 8a) and [25]. In that case errors in the designations of phase regions in these papers are connected with the fact that the sections of the solidus $\mathrm{s}_{\mathrm{B}(\mathrm{C})}$ and solvus $\mathrm{v}_{\mathrm{B}(\mathrm{C})-} \mathrm{R}_{2}$ surfaces - curves 5-6, 6-20 (Figure $8 \mathrm{~b}$ ) are lost in the appropriate sections of the $3 \mathrm{D}$ models. At the same time, it should be noted that the curve of solvus (the curve 6-18 in Figure 8d) of the model section cannot be very close to the temperature axis, when the disintegration cupola is present, which in this case must be assumed, also, in the section, constructed in [26] Figure 8c. They should move away from the axis in order "to give a place" for the trace of the section of the disintegration cupola, as in Figure $8 \mathrm{~b}$. Thus, the final version of the T-x-y diagram 3D computer model consists of 60 surfaces and 24 


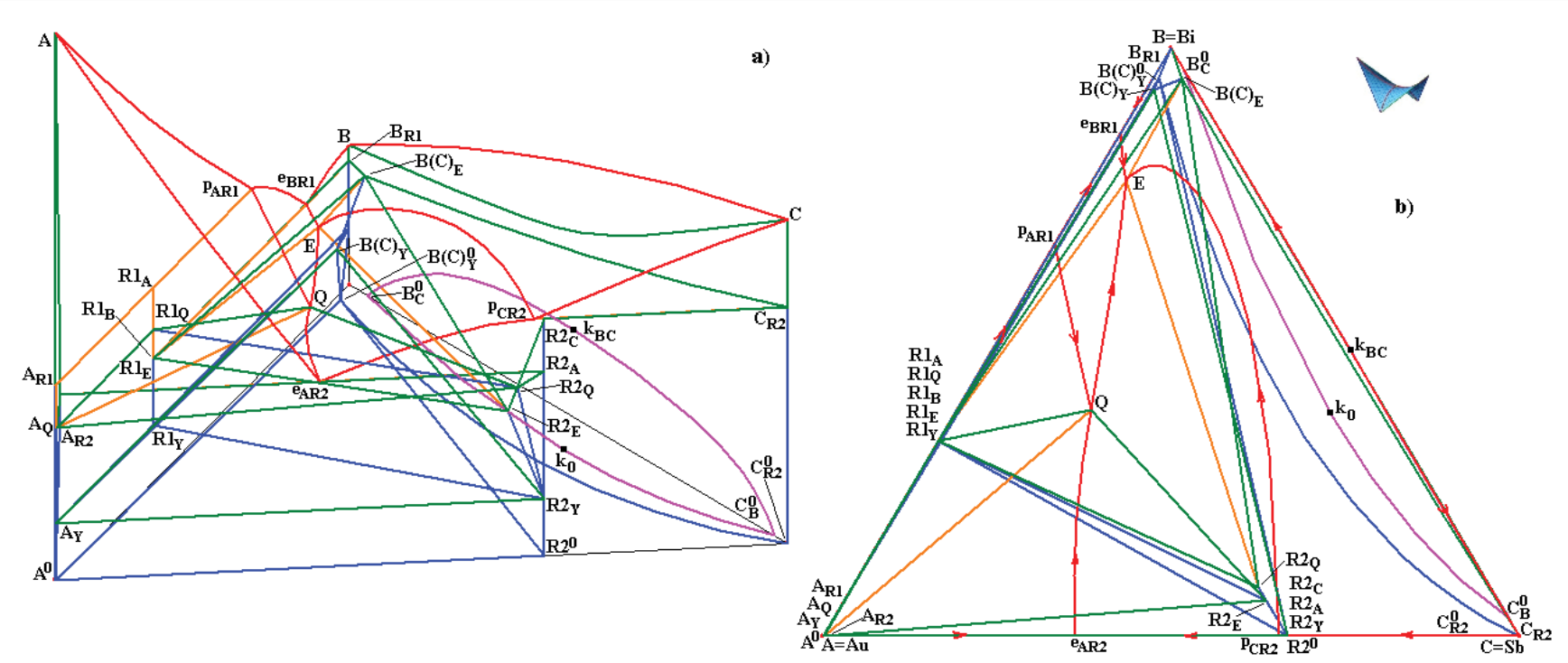

Figure 6: 3D computer model of the Au-Bi-Sb=A-B-C T-x-y diagram, designed according to data [12], but with the added surfaces of solidus $\mathrm{s}_{\mathrm{B}(\mathrm{C})}$ and solvus $\mathrm{V}_{\mathrm{B}\left(\mathrm{C}_{\mathrm{C}} \mathrm{R} 2\right.} \cdot(\mathrm{a}) ; \mathrm{x}-\mathrm{y}$ projection (b).

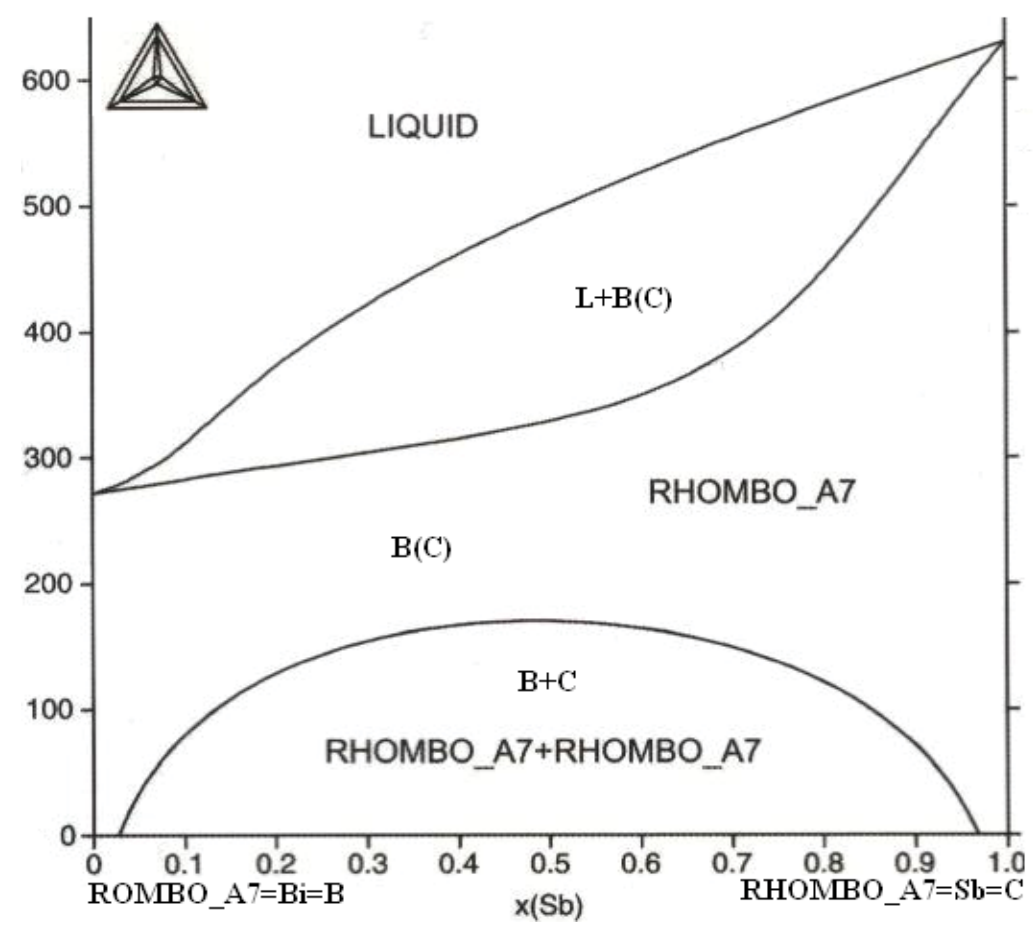

Figure 7: Binary system Bi-Sb [12] (the axis of temperature is marked in ${ }^{\circ} \mathrm{C}$ ).

phase regions and reproduced the data of [12], but with the added surfaces of solidus $\mathrm{s}_{\mathrm{B}(\mathrm{C})}$ and solvus $\mathrm{v}_{\mathrm{B}(\mathrm{C})} \mathrm{R}_{2}$. Traces of these surfaces are shown by dashed lines on the 20 at\% Bi isopleth (Figure $8 \mathrm{~b}$ ).

\section{Conclusion}

It is convenient to use the 3D computer models of T-x-y diagrams, designed according to the data of the different authors, for the agreement of the sections and for searching of contradictions in calculations or incorrect interpretation of experiment. Despite the fact that the binary system Au-Bi is well studied $[14,16,19]$ and it shown in the publications
$[16,19]$ that the solid solution on basis of the compound $\mathrm{Au}_{2} \mathrm{Bi}$ does not exist in the ternary system at temperatures below $110^{\circ} \mathrm{C}$, the analysis of isopleths, carried out with the aid of two versions of the Au-Ag-Bi T-x-y diagram 3D computer model, constructed according to the data $[12,17]$, showed that the decomposition this solid solution was not considered in [12] and [17]. Therefore the low-temperature part of these sections must be corrected. The correct form of section is shown in the Figure 5f. In order to be confident in the correctness of the AuSb-Sn system description in [22-24], it is necessary to explain, actually the compound $\mathrm{Sb}_{2} \mathrm{Sn}_{3}$ is decomposed at $242.2^{\circ} \mathrm{C}$ as in [12], or the 

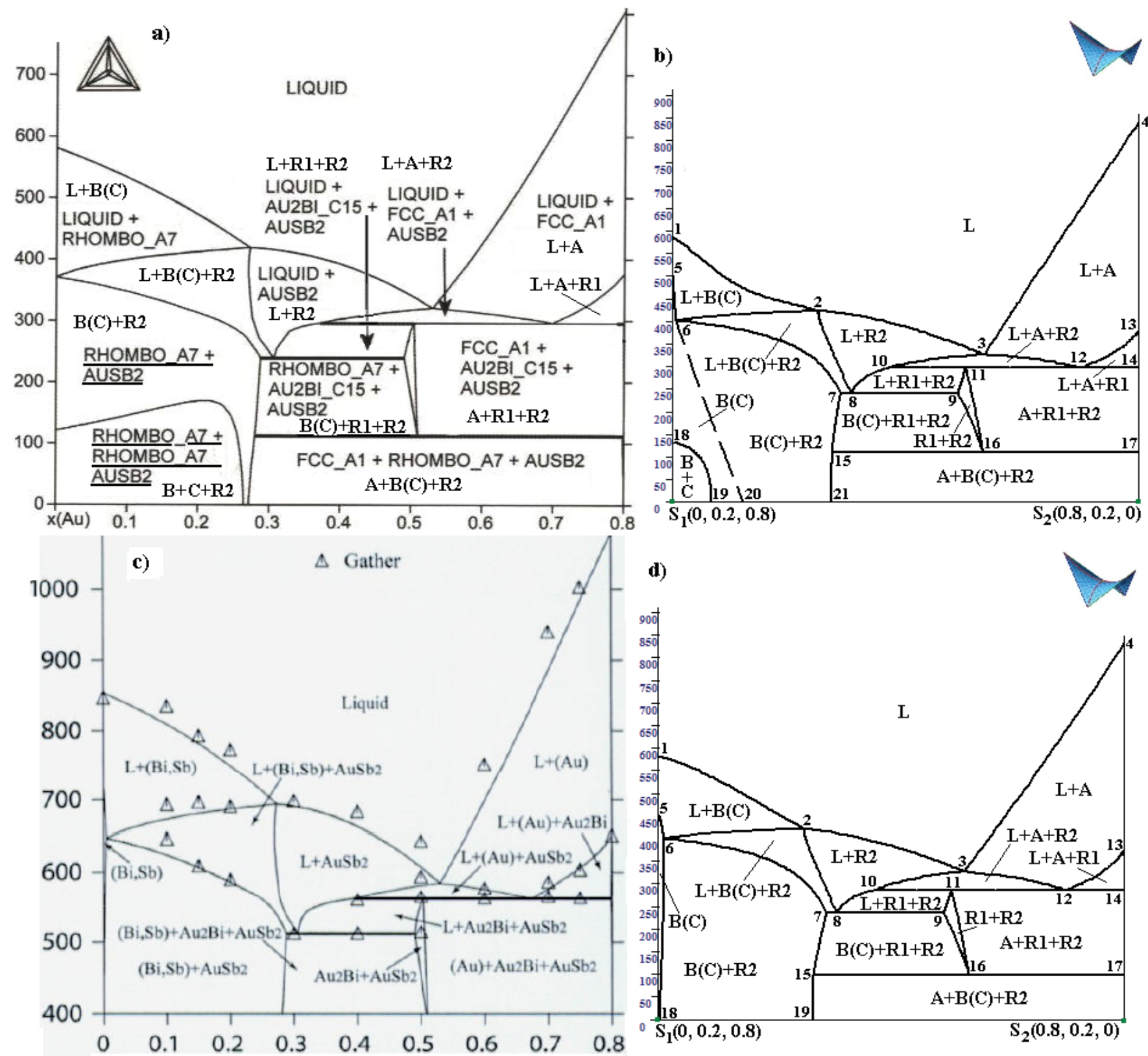

Figure 8: Isopleth $\mathrm{S}_{1}(0,0.2,0.8)-\mathrm{S}_{2}(0.8,0.2,0)$ of the Au-Bi-Sb: [12] (a): [26] (c): and 3D models according to data [12] (b): (the axis of temperature is marked in $\left.{ }^{\circ} \mathrm{C}\right)$ and [26] (d): (sections of the added surfaces of solidus $\mathrm{S}_{\mathrm{B}(\mathrm{C})}$ and solvus $\mathrm{v}_{\mathrm{B}(\mathrm{C}) \mathrm{R} 2}$. are drawn with dashed lines).

temperature boundaries of its existence are stretched to $0^{\circ} \mathrm{C}$ as it shown in [22] Fragment of the 17 at \% Ge isopleth is not correctly in Figure 8 The analysis, carried out with the aid of three versions of the AuBi-Sb T-x-y diagram 3D computer model for publications $[12,25,26]$, showed that: a) sections of the solidus $\mathrm{s}_{\mathrm{B}(\mathrm{C})}$ and solvus $\mathrm{v}_{\mathrm{B}(\mathrm{C})} \mathrm{R}_{2}$ surfaces in isopleths of the 3D computer models by curves 5-6 and 6-20 (Figure $8 \mathrm{~b}$ ), 5-6 and 6-18 (Figure $5 \mathrm{~d}$ ), are missed in sections of the diagram in [12] (Figure 8a) and in [25] b) phase regions $\mathrm{Bi}(\mathrm{Sb})$ and $\mathrm{Bi}+\mathrm{Sb}$ are missed in the same sections in [12] (Figure 8a) and in [25];c) the cupola of the solid solution $\mathrm{Bi}(\mathrm{Sb})$ disintegration to bismuth and antimony (Figure $8 \mathrm{c}$ ), which is assigned by the binodal of the Bi-Sb binary system [12], is lost in [26] (Figure 6). Most preferable is the version of the T-x-y diagram 3D model, which is reconstructed according to the data of [12], but with the added surfaces of solidus $\mathrm{s}_{\mathrm{B}(\mathrm{C})}$ and solvus
$\mathrm{V}_{\mathrm{B}(\mathrm{C})} \mathrm{R}_{2}$ (Figure 6). At the same time, it is possible only to speak, that the structure of the ternary system phase regions near the binary system $\mathrm{Bi}-\mathrm{Sb}$ at temperatures below $150^{\circ} \mathrm{C}$ is contradictory and requires an additional experimental study.

\section{Acknowledgements}

This work was been performed under the program of fundamental research SB RAS (Project 0336-2016-0006), it was partially supported by the RFBR (Projects 15-43-04304, 17-08-00875) and the RSF (Project 17-19-01171).

\section{References}

1. Lutsyk V, Vorob'eva (2009) From topology to computer model: ternary systems with polymorphism. Abstracts of the international conference on phase diagram calculations and computational thermochemistry (CALPHAD XXXVIII), Prague, Czech Republic, p: 66. 
Citation: Lutsyk VI, Vorobeva VP (2017) Verification of Phase Diagrams by Three-Dimension Computer Models. Mod Chem Appl 5: 215. doi: $10.4172 / 2329-6798.1000215$

Page 10 of 10

2. Lutsyk VI, Vorob'eva (2010) Computer models of eutectic-type T-x-y diagrams with allotropy. Two inner liquidus fields of two low-temperature modifications of the same component. J Therm Anal Calorim 101: 25-31.

3. Rhines FN (1956) Phase Diagrams in Metallurgy: Their development and application. McGraw-Hill Book Company, MC. New York-Toronto-London.

4. Prince A (1966) Alloy Phase Equilibria. Elsevier Publ Comp AmsterdamLondon, New York.

5. Lutsyk VI, Vorob'eva, Zelenaya AE (2015) 3D reference book on the oxide systems space diagrams as a tool for data mining. Solid State Phenomena 230: $51-54$.

6. Lukas HL, Henig ET, Petzow G (1986) 50 Years Reaction Scheme after Erich Scheil. Z Metallkd 76: 360-367.

7. Dinsdale A, Kroupa A, Watson A (2012) COST Action MP0602 - Handbook of high-temperature lead-free solders - Atlas of phase diagrams 1: 218.

8. Lutsyk VI, Vorob'eva (2016) 3D model of the T-x-y diagram of the Bi-In-Sn system for designing microstructure of alloys. Rus J Inorg Chem 61: 188-207.

9. Lutsyk VI, Vorob'eva, Shodorova SY (2015) Determining the conditions for changes of the three-phase rreaction type in a V-Zr-Cr systems. Rus J Phys Chem A 89: 2331-2338

10. Lutsyk VI, Vorob'eva, Shodorova SY (2016) Verification of the T-x-y diagram of the Ag-Au-Bi system using a 3D computer model. Rus J Inorg Chem 61: 858-866.

11. Lutsyk VI, Vorob'eva (2015) Three-dimensional model of phase diagram of Au$\mathrm{Bi}-\mathrm{Sb}$ system for clarification of thermodynamic calculations. Rus J Phys Chem A 89: 1715-1722.

12. Dinsdale A, Watson A, Kroupa A (2008) Atlas of phase diagrams for lead-free soldering compiled by COST 531 1: 277

13. Wang J, Leinenbach C, Roth M (2009) Thermodynamic description of the AuGe-Sb ternary system. J Alloys Compd 485: 577-582.

14. Zoro E, Dichi E, Servant C, Legendre B (2005) Phase equilibria in the Ag-Au-Bi ternary system. J Alloys Compd 400: 209-215.
15. Zoro E, Boa D, Servant C, Legendre B (2005) Enthalpies of mixing of the liquid phase in the ternary system Ag-Au-Bi. J Alloys Compd 398: 106-112.

16. Servant C, Zoro E, Legendre B (2006) Thermodynamic reassessment of the Au-Bi system. CALPHAD 30: 443-448.

17. Zoro E, Servant C, Legendre B (2007) Thermodynamic assessment of the AgAu-Bi system. CALPHAD 31: 89-94.

18. Zoro E, Servant C, Legendre B (2007) Thermodynamic assessment of the AgAu-Bi and Ag-Au-Sb systems. J Therm Anal Calorim 90: 347-353.

19. Chevalier PY (1988) Thermodynamic evaluation of the Au-Bi system. Thermochim Acta 130: 15-24.

20. Zakharov AM (1990) State diagrams of binary and ternary systems.

21. Fedorov PP (2010) Third law of thermodynamics as applied to phase diagrams. Rus J Inorgan Chem 55: 1722-1739.

22. Chen SW, Chen PY, Wu HJ, Chiu CN, Huang YC, et al. (2008) Phase equilibria of Sn-Sb-Ag ternary system (I): experimental. Metall Mater Trans A 39: 3191-3198.

23. Gierlotka W, Huang YC, Chen SW (2008) Phase equilibria of Sn-Sb-Ag ternary system (II): calculation. Metall Mater Trans 39: 3199-3209.

24. Chen SW, Chen CC, Gierlotka W, Zi AR, Chen PY, et al. (2008) Phase equilibria in the Sn-Sb binary system. J Electron Mater 37: 992-1002.

25. Manasijevic D, Minic D, Zivkovic D, Zivkovic Z (2008) Experimental study and thermodynamic calculation of Au-Bi-Sb system phase equilibria. J Phys Chem Solids 69: 847-851.

26. Wang J, Meng FG, Liu HS, Liu LB, Jin ZP (2007) Thermodynamic modeling of the Au-Bi-Sb ternary system. J Electron Mater 36: 568-577.

27. Prince A, Raynor GV, Evans DS (1990) Phase diagrams of ternary gold alloys, London: the Institute of Metals.

28. Voskov AL, Dzuban AV, Maksimov AI (2015) TernAPI program for the calculation of ternary phase diagrams with isolated miscibility gaps by the convex hul method. Fluid Phase Equilibria 388: 50-58. 